\title{
Peer-to-Peer \\ Accommodation Networks: \\ Pushing the boundaries
}

Sara Dolnicar

(G) Goodfellow Publishers Ltd 
British Library Cataloguing in Publication Data: a catalogue record for this title is available from the British Library.

Library of Congress Catalog Card Number: on file.

DOI 10.23912/9781911396512-3454

e ISBN 978-1-91196-53-6

Paperback ISBN: 978-1-911396-52-9

Hardback ISBN: 978-1-911396-51-2

Copyright (C) Sara Dolnicar, 2018

All rights reserved. The text of this publication, or any part thereof, may not be reproduced or transmitted in any form or by any means, electronic or mechanical, including photocopying, recording, storage in an information retrieval system, or otherwise, without prior permission of the publisher or under licence from the Copyright Licensing Agency Limited. Further details of such licences (for reprographic reproduction) may be obtained from the Copyright Licensing Agency Limited, of Saffron House, 6-10 Kirby Street, London EC1N 8TS.

Open access:

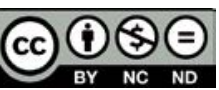

Except where otherwise noted, this work is licensed under

a Creative Commons Attribution 3.0 Unported License.

To view a copy of this license, visit http://creativecommons.org/licenses/by/3.0

All trademarks used herein are the property of their repective owners, The use of trademarks or brand names in this text does not imply any affiliation with or endorsement of this book by such owners.

Typesetting by D.S. Pears, Hampshire

Cover design by Cylinder

Illustrations by Peta Hewitt 


\title{
Systems
}

\author{
Denise Lawungkurr Goodfellow, Thompson-Nganjmirra \\ family
}

Anne Hardy, Tasmanian School of Economics and Business, University of Tasmania, Australia

Sara Dolnicar, Department of Tourism, UQ Business School, The University of Queensland, Australia

\begin{abstract}
Peer-to-peer accommodation networks are considered a relatively new phenomenon. But how new are they really? This chapter explores social interactions on these networks and draws parallels to people whose existence has been dated back 65,000 years: Australian Indigenous communities. Despite their very different appearance, rules of engagement and context, traditional communities have far more in common with modern day neo-tribes that may have been thought.
\end{abstract}

Peer-to-peer accommodation networks are still considered a relatively new phenomenon in tourism accommodation, and one that challenges existing structures of the sector. At the core of peer-to-peer networks stand interpersonal relationships that develop between strangers. These relationships between 'ordinary people' - as opposed to the highly standardized business interactions between tourists and commercial accommodation providers - drive the success of peer-to-peer accommodation networks. The most successful networks - such as Airbnb - place interpersonal communication at the center of their platform. Without this, it is virtually impossible to make space available for trading on a peer-to-peer network or to rent accommodation on such networks (Chapter 3).

Please reference as: Goodfellow, D. L., Hardy, A. and Dolnicar, S. (2017) Chapter 20 Communication-Regulated Social Systems, in S. Dolnicar, Peer-to-Peer Accommodation Networks: Pushing the boundaries, Oxford: Goodfellow Publishers, pp. 225-234, https:// dx.doi.org/10.23912/9781911396512-3618 
In this respect, peer-to-peer accommodation networks are similar to some of the oldest societies on our planet: Indigenous Australians. Peer-to-peer accommodation networks act as modern day neo-tribes. The functioning of neo-tribes relies heavily on personal transfer of information between individuals.

This chapter explores the parallels between peer-to-peer accommodation networks and Indigenous Australian communities using auto-ethnography and netnography. Auto-ethnography is a qualitative approach that allows the nuances, details, and meanings of a culture to be explored from an insider's perspective (Patton, 2001; Hughson, 2007; Greenacre et al., 2013). Here, autoethnographies from a member of a traditional Australian Indigenous community and two members of a modern neo-tribe are used. The first author of this chapter - Denise Lawungkurr Goodfellow - was adopted into an Aboriginal family by a Larrakia elder in 1983. Denise's son - at the age of three - became a 'little daddy' to a newborn boy and his sister (Goodfellow, 2007). Denise's insights serve as the primary source of information about the role of interpersonal communication in the functioning of Indigenous Australian society, particularly the Kunwinjku family, to which she belongs. The second and third authors serve as the data sources for the second auto-ethnography; they are both hosts on peer-to-peer accommodation networks and are able to draw on their personal experiences of host and guest behaviors in neo-tribes. A netnography of a statewide Facebook Airbnb hosting forum (Chapter 16) complements the research. Netnography is the process of gathering data via computer-mediated communication to inform insights into the interactions and workings of a community (Kozinets, 2002).

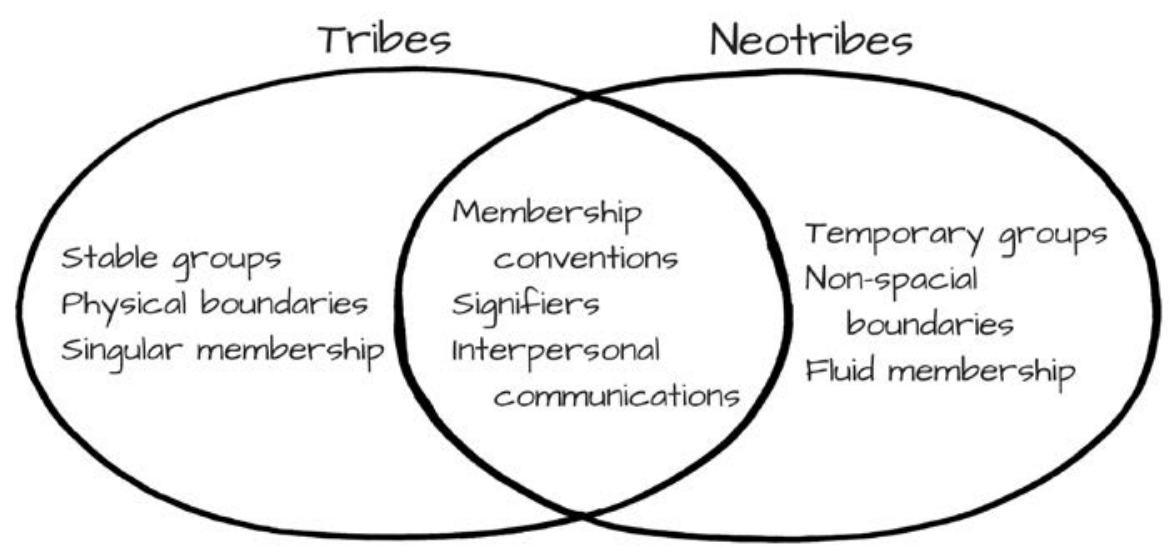

Figure 20.1: Tribes, neo-tribes and what they have in common

Figure 20.1 shows key characteristics of traditional tribes and neo-tribes (Maffesoli, 1996; Cova and Cova, 2002; Hardy and Robards, 2015): neo-tribes are temporary, rather than permanent, and stable in nature. They do not have 
defined physical boundaries, and coalesce temporarily in virtual or physical meeting spaces; members can move geographically without having to give up membership of a neo-tribe. Even on peer-to-peer accommodation networks, which offer space at a particular geographical location, it is not necessary for members of the network to disclose their place of residence. Conversely, tribes are very much bound to the geographical boundaries of their land. Tribes typically demand exclusivity of membership; neo-tribes do not (Cova \& Cova, 2002). A member of Airbnb can also be a member of a forum of Airbnb hosts (see Chapter 16) and even a member of another peer-to-peer accommodation network that competes with Airbnb (see Chapter 6).

The three things both tribes and neo-tribes have in common are that they: have membership conventions, including behavioral conventions attached to status; use signifiers to indicate status; and rely heavily on interpersonal communication for the very functioning of the community. This chapter explores these common characteristics in detail, and in doing so, draws parallels between peer-to-peer networks and Indigenous Australian communities.

\section{Membership conventions}

Membership stands at the center of communities. To understand the functioning of both tribes and neo-tribes, it is critically important to know how people become members, stay members, or lose membership.

In 1983, Denise Lawungkurr Goodfellow was an alderman on the Darwin City Council. Bagot Aboriginal Reserve was within her ward, and Denise wanted to represent the interests of the local Larrakia residents, but members did not trust her because she was 'white' and not part of their community. The Bagot Council president (Mrs. Thompson) asked her to catch a snake to test her resolve to represent the residents. To do this, Denise waded around a crocodileinfested lagoon for four hours. She undertook this challenge, although she was unsure whether the Aboriginal people present would help her, should she be attacked by a crocodile. She was not attacked and returned with a python, proving her commitment and trustworthiness to the community. However, upon her return, rather than being celebrated by the wider Darwin community, Denise was threatened with prosecution by the Conservation Commission for catching protected wildlife. To protect her from prosecution, Mrs. Thompson adopted her, making her a member of a Kunwinjku clan. This incredible process resulted in Denise's family members being given 'skin names' and 'dreamings'. As members of the clan, they were also expected to abide by the community's rules of behavioral standards. News of Denise's adoption spread quickly through word of mouth and Mrs. Thompson brought many relatives (Larrakia, Kunwinjku, and others) to Denise's home to meet her. 
Becoming a member of a peer-to-peer accommodation network does not involve catching pythons. In fact, it is not even obvious that there are any hurdles at all to becoming a member, given that anyone with an internet connection can sign up. But - while signing up allows you to be on the platform and interact with others there - you are not taken seriously as a member before you have your first review, both as a host and as a guest. Chapter 17 illustrates one example of someone who wishes to become a member but misjudges the importance of this initiation ritual. Chapter 16 illustrates how new members who are unaware of the social conventions of the community are disrespected by other members. Reviews are the glue between strangers on peer-to-peer accommodation networks. The credibility of members depends on their peerto-peer network curriculum vitae (P2P-CV, Chapter 1), the sum of all reviews written about them. The first confirmed booking initiates members into the community.

Within peer-to-peer networks we can also see the formation of 'sub-tribes', whose existence is centerd on particular issues, interests or destinations, many of which have distinctive membership conventions. Our netnographic research explored an Airbnb Facebook forum for a particular destination, where hosts share their experiences with one another, offer advice, and lobby for the rights of Airbnb hosts (Chapter 16). The forum has an 'introduction' convention whereby hosts new to it introduce their listings to fellow members and ask for feedback, as means to have their new membership validated. For example:

So, I uploaded my two rooms at $4.30 \mathrm{pm}$ and by $6 \mathrm{pm}$ I had a booking. I now have three Germans in my Margate home. Auto price set was $\$ 60$. Is that reasonable for Margate?

This question elicited many responses from fellow host forum members, who offered suggestions, such as ensuring that cleaning costs and time were included, as well as suggestions on alternative, particularly higher, pricing.

Of course, there are major differences between traditional communities and neo-tribes in terms of how one becomes a member. In Indigenous Australian communities, the primary pathway into membership is birth. You cannot be born into a neo-tribe. If you have not been born or married into an Indigenous Australian community, you cannot sign up or apply for membership; you have to be invited. To become a member of a neo-tribe you can simply sign up, which gives the impression that it is very easy to become a member. But the true initiation comes later, and may not even be identified as such by many. However, both tribes and neo-tribes use a process of confirmation to accept new members and affirmations commonly follow once new members arrive. 
At the opposite end of the spectrum, membership status can also be removed if network members do not display behaviors in line with the neo-tribe's expectations. On the Airbnb host forum that we followed, badly behaved guests have their profiles made into a screenshot and are named, shamed, and outed amongst hosts who detail their misdemeanours:

Beware! Good evening today I had a fake booking ( 3 days) - this is how it reads:

In addition to this, peer-to-peer network facilitators can also punish and remove members from the network. Airbnb is doing this regularly if there is evidence of members not behaving in line with Airbnb's behavioral expectations.

Exclusion also occurs in Indigenous Australian communities, although the approach to expressing that someone is no longer welcome as part of the community is less black and white than it is on peer-to-peer networks. Denise's ex-husband, for example, was not viewed very favorably by her Aboriginal family for various comments he made. The way the family handled this challenge was to 'sing' to Denise (cast spells) to make her fall out of love with him.

The feeling among remaining members that these excluded people are no longer part of their community can last beyond their lifetimes. In the case of Denise's older sister, people actively avoided attending the funeral of her daughter, a 'long-grass' dweller who died in Darwin. Another sister called out to neighbors over the back fence to attend the funeral. They did not.

\section{Signifiers}

The highest status in Indigenous Australian communities is that of an Elder. There are no restrictions on who becomes an Elder. Elders can be women or men, and they do not have to be of a certain age. Rather, it is their actions as a community member that earn the respect of other community members, leading to them becoming an Elder. Elders display skills, knowledge and wisdom, and are seen as leaders in their community. The term 'old lady' is one of respect and honor rather than a slight, as it is often regarded in Western societies.

A similar signifier is used by peer-to-peer accommodation network facilitator Airbnb: that of the Superhost. Superhosts status - like that of Elders - does not depend on age, gender, or even length of membership in the neo-tribe. Rather, it depends solely on behaviors displayed as a community member. To become a Superhost, hosts must have a five-star rating by at least $80 \%$ of their guests; they must have at least ten bookings in a year; they must not have canceled any bookings; and must have responded to $90 \%$ of all booking enquiries within 24 hours of an enquiry. If all of these criteria are met, a signifier - a Superhost badge - appears on the host's profile picture, and this is visible to 
all network members. Superhost status affects price (Chapter 12) and future bookings (Xie and Mao, 2017).

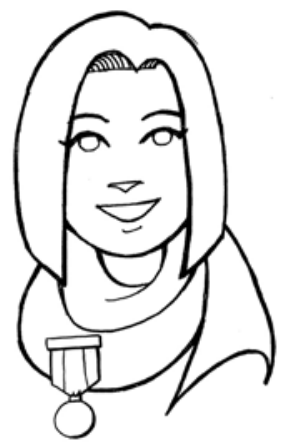

Figure 20.2: Example of what the Superhost signifier looks like

As well as displaying Superhost badges, some hosts go to great lengths to assert their authority by being very active on networks, sharing their experiences and offering their opinions, to illustrate their status as experienced hosts. They update fellow hosts on policy changes, offer advice on the best cleaners and ancillary services, and tag Airbnb managers into conversations when trying to advocate for change. This behavior reinforces their power and status within the neo-tribe. But even among regular guests and hosts - those without Superhost status - signifiers from their online profiles can be used to assess their commitment to the community and the alignment of their behavior with the expectations of the network. The P2P-CV - the total listing of all reviews about a member - reveals everything worth noting about the member from the perspective of other members.

A similar signifier in Indigenous Australian communities are names given to people. Denise Goodfellow, for example, was named Lawungkurr by the Elders after an ancestral woman still respected for her mediation skills. The meaning of the name is well understood within the community, thus serving as a signifier of Denise's particular ability in a certain area.

\section{Interpersonal communication}

In addition to signifiers that both Aboriginal communities and Airbnb neo-tribes have in common, there is evidence that both use interpersonal communication and collaboration to shape the way in which outsiders view the community.

In the case of the Aboriginal communities, the Baby Dreaming Project serves as a good example of this occurring. It developed serendipitously because Denise - a birdwatching guide - hosted birdwatchers in her garden. Initially, her Aboriginal relatives were unsure about the visitors and avoided interacting with them. But from 1983, the date of Denise's adoption, the Kunwinjku 
Elders of Western Arnhem Land came to stay at her home, where they met the birdwatchers, mostly senior American couples. The Elders expressed that they liked the birdwatchers, and in 1988 asked Denise for her assistance in starting a small tourism project. But 'Kunwinjku relatives only wanted visitors with whom they felt comfortable' (Goodfellow, 2017: 5). Reverend P. Nganjmirra, a Kunwinjku Elder, reported that - within weeks - Bininj (northwestern Top End Aboriginal people) throughout the region knew about the project and were interested. It took much longer for those members of the clans who had not been to Denise's home to meet the birdwatchers to approve.

Visitors started arriving. While the tourists' camping sites were not colocated with the Aboriginal community's homes, tourists and Aboriginal people cooked and ate together. Often it was unplanned moments that brought people together and developed trust in one another. For example, when a couple of Kunwinjku people at the outstation Kudjekbinj had health difficulties, two medical specialists who were part of a tour group treated them. This gesture, and word spreading about this gesture, connected community and visitors, and many more Aboriginal people came to see the doctors with their own medical problems. The Baby Dreaming Project serves as an example of the efficiency of interpersonal communication and how the sharing of experiences achieved positive outcomes in Aboriginal communities.

On peer-to-peer accommodation networks, interpersonal communication is also regularly used to share information amongst hosts and to assist one another in the provision of a unique and authentic experience that reflects their destination. This non-monetary exchange of information regularly occurs on the Facebook Airbnb host forum which we followed. Like Aboriginal communities, we witnessed stories being shared to assist hosts in improving their experiences. It was not unusual to see hosts seeking advice on how to provide unique experiences for unusual guests.

Post: We have our first honeymoon couple coming on 6 August for 5 nights. Suggestions for something nice to do for them - I was thinking a bottle of bubble and few goodies - bearing in mind we are budget and only charge $\$ 55$ per night.

In this instance, hosts suggested ideas such as offering them home-made biscuits, flowers, and/or a decorative candle to celebrate the occasion.

Perhaps the most powerful occurrence on interpersonal communication within the Airbnb neo-tribe is the feedback given to hosts from guests. Airbnb relies on reviews to improve experiences and to build trust between network members. Feedback is given in two ways: private feedback accessible only to the host, and public feedback visible to all network members. Feedback can be 
very detailed, as the example below shows. This was private feedback given to the second author - Anne Hardy - by one of her guests.

Only a couple of recommendations. The beautiful flowers you provided had a very, very strong fragrance, my friends were overpowered. I would recommend maybe a smaller bunch of the flowers as it was quite over powering. I would recommend putting extra sheets and blankets in the cupboard as we only had the fitted sheet for the futon. We didn't discover we were short until it was late and didn't want to disturb. Maybe a thin mattress to lay on top of the futon as it was a little uncomfortable. Oh and one other thing, when we arrived we were a little confused if we were at the right property as there was a sign out front which I thought may have been the name of another property. We did enjoy our stay and will be back - we've just bought a home in North Tassie :)

Moving the shoes from the stairwell would give the feeling of more of a private rather than shared entry point, it's a small thing but I think it would make a difference.

This detailed feedback, when publicly visible, allows hosts to respond. If the feedback is negative, there is a community expectation that the host will respond. Not responding is punished by the community because potential future guests are not sure if they can trust that the particular host will offer a positive experience. What network members say about one another affects how the network functions.

This is very similar to Australian Indigenous communities. Because the spoken word is of critical importance for information transfer in Aboriginal communities, it functions as a key regulatory mechanism. If members of Indigenous Australian communities are seen not to be sharing or not behaving in line with community expectations, they are talked about. And Bininj women sometimes express their anger about others who spread rumors about them on Facebook, a medium that has been embraced by Aboriginal communities, possibly because it offers a more effective way of maintaining essentially the same traditional communication patterns.

Another example is that of untrue information spread about a female white art dealer, who was accused of selling Aboriginal art for her personal benefit. It was rumored that all the money she earned selling Aboriginal art allowed her to build an apartment block, which she named after an ancestral Kunwinjku. If the spoken word is untrue, the spoken word is also used to correct information. Speaking about the irresponsible behavior or tourists and tour operators is also common. The Mirrar, traditional owners of western Kakadu National Park, for 
example, warned the Kunwinjku about becoming involved in tourism because of the way tourists and tour operators behaved.

\section{Conclusions}

This chapter has illustrated that, despite traditional communities and modern neo-tribes appearing to be very different, they both rely on membership conventions, signifiers and interpersonal communication to regulate community functioning. In the case of Airbnb, the initiation as a true member of the network includes receiving one's first review; and the status signifier of Superhost. Similarly, traditional communities have rituals for new members; signifiers of status such as being an Elder; and verbal communication regulates the behavior in the everyday context, and is used to punish misbehavior.

These examples illustrate that - while boundaries, longevity and performance spaces may differ amongst tribes and neo-tribes - the urge to merge is an age-old phenomenon. Our desire to feel a sense of fellowship, have a sense of belonging, and be amongst like-minded people transcends time and space. And at the heart of this stands interpersonal communication that acts as the glue that binds these factors together.

\section{Questions for future research}

This chapter represents an initial investigation into the parallels that exist between the functioning of tribes and neo-tribes. Many more parallels are likely to exist which have not been explored yet, but would be interesting to investigate in future. In addition, it would be interesting to study whether people who are members of traditional tribes, such as Indigenous Australian communities, are attracted to neo-tribes because they are possibly more familiar with the rules in such social structures. Indigenous Australian communities have wholeheartedly embraced Facebook, which may serve as an indicator that they feel comfortable engaging in neo-tribes. Another key question of significance to Indigenous Aboriginal communities is whether they could harvest peer-to-peer accommodation networks to their benefit by hosting. This may be particularly promising because the host has control over who to accept; birdwatching couples may represent an excellent target segment. The experiences offered would be unique and would most certainly attract significant demand. The question, however, is how well the reality of guests who may not be willing to adjust to the community lifestyle would work. The Baby Dreaming Project is evidence that it can work, if managed carefully. 


\section{Acknowledgments}

We thank Denise's Bininj family. Relatives like Reverend P. Nganjmirra (now deceased) and his wife, Stephanie Thompson Nganjmirra, set the benchmark in courage and decent behavior at times when others around her (including the government) did not. Now a new generation of Bininj speak up - much in contradiction to their traditions - against injustice being experienced by their people. Anthropologist Colin Turnbull wrote that for the hunter-gatherer peoples in Africa 'kindness, generosity, consideration, ... honesty ... compassion, charity and other (characteristics)' are not virtues but 'necessities for survival' (1972: 31). Denise found all those 'necessities' within Bininj members of her family. However, as the neo-tribes have shown, they also apply to the wider society!

Ethical clearance was obtained from The University of Queensland Human Ethics Committee (approval number 2017001021).

\section{References}

Cova, B. and Cova, V. (2002) Tribal marketing: The tribalisation of society and its impact on the conduct of marketing, European Journal of Marketing, 36, 595-620.

Finn, J. (2017) New York Airbnb host who canceled a reservation because the tenant was Asian is fined $\$ 5,000$ and forced to take a college course in Asian-American studies, retrieved on August 2, 2017 from http://www. dailymail.co.uk/news/article-4694962/Airbnb-host-fined-cancelling-Asianwomans-reservation.html.

Goodfellow, D.L. (2007) Quiet Snake Dreaming. Darwin: Scrubfowl Press.

Goodfellow, D.L. (2017) Building and maintaining trust - a little tourism project in Western Arnhem land, CAUTHE 2017, University of Otago, Dunedin, New Zealand.

Greenacre, L., Freeman, L., and Donald, M. (2013) Contrasting social network and tribal theories: An applied perspective, Journal of Business Research, 66, 948-954.

Hardy, A. and Robards, B. (2015) The ties that bind: Exploring neo-tribal theory's relevance to tourism, Tourism Analysis, 20 (4), 443-454.

Hughson, J. (2007) A tale of two tribes: Expressive fandom in Australian soccer's A-league, Culture, Sport, Society, 2 (3), 10-30.

Kozinets, R. (2002) The field behind the screen: Using netnogrphy for marketing research in online communities, Journal of Marketing Research, 29 (1), 61-72.

Maffesoli, M. (1996) The Time of the Tribes. London: Sage. 
Patton, M.Q. (2001) Qualitative Research and Evaluation Methods. London: Sage. Turnbull, C.M. (1972) The Mountain People. New York: Simon \& Schuster.

Xie, K.L. and Mao, Z. (2017) The impacts of quality and quantity attributes of Airbnb hosts on listing performance, International Journal of Contemporary Hospitality Management, DOI: 10.1108/IJCHM-07-2016-0345. 